\title{
COMPUTER LITERACY IN THE NETHERLANDS
}

\author{
G. J. Carleer \\ Twente University of Technology, Department of Education, P.O. Box 217, 7500 Enschede,
} The Netherlands

\section{INTRODUCTION}

With the exception of some research and development projects, computers in primary schools are very rare in The Netherlands. The domain of the secondary education is characterized by small-scale research projects and, recently, by an explosion of grass-roots developments and of private initiatives on the use of computers in schools. The Ministry of Education and Sciences started in 1981 with developing a policy, by installing an internal working group and a national Advisory Committee on Education and Information Technology. In September 1982 the Minister of Education and Sciences presented his policy report "Education and Information Technology" to the Parliament. This fact, together with the appearance of the first advice of a national Advisory Committee on Education and Information Technology and the creation of the Centre for Education and Information Technology, which has to serve Dutch Schools with information and advice about the introduction and use of computers in education, indicates that a start has been made with a national policy and a plan has been initiated for nationwide research and development projects.

The content of this paper is restricted to the use of computers in lower secondary education, especially the topic "learning about information technology".

In the following sections we will put forward successively the policy report, the advice and the tasks of the Centre, the characteristics of the development and implementation of computer literacy in The Netherlands and, finally, the planned nationwide survey. Where necessary, some information will be given on the Dutch educational system.

\section{IDEAS ON COMPUTERS IN SCHOOLS}

One, but not the only, reason why the national government is urged to formulate its own policy, is the centralized financing of the Dutch Educational System[1]. On the one hand, secondary education is financed directly by the central government, although additional equipment, like computers, may be provided by municipal authorities, as long as private and state schools of the same type receive the same extra funds. On the other hand, schools are free to a large extent to arrange their own curricula. Private education, with its own curricula is common in The Netherlands. These private schools are either based on religious convictions-catholic $(37 \%)$ or protestant $(25 \%)$ - or other (e.g. non-religious pedagogical) principles $(11 \%)$, as public Montessori, Doltan and Jena schools. These three private sectors and the fourth sector, state education (i.e. that education provided by central or local government) are fully financed by the central government, but they have great autonomy concerning their curricula. These two aspects, the financing of school materials, equipment and infrastructure (e.g. salaries, microcomputers) and the autonomy of curricula, oblige the government to clarify its national educational policy in general, and more specific the use of computers in schools.

With the presentation of his policy report in September 1982, the Minister of Education and Sciences has set up a framework for his policy intentions. The two starting points of the policy report of the Minister of Education and Sciences, are of a socio-economic and a socio-cultural nature.

"As far as the first is concerned, it is important, given present technological developments, that professionals will be educated in informatics as well as in fields making intensive use of information technology. Moreover, it is desirable that, following formal education, adults should attend 
regularly short courses or workshops to update their knowledge. Because of latterday technological developments many professions will change continuously, in a way for which students must be prepared. This implies that teaching about information technology (or computer science) must concentrate on their basic skills as well as their innovative qualifications so that they learn continuously to keep up with developments. Another implication is that teaching about information technology should not be overconcentrated on just one professional application. Bearing in mind these considerations, the policy report proposed an adaptation of teaching programmes in vocational/professional education.

By contrast, the implication of the sociocultural starting point is that all children aged 15 or less have to learn about information technology and some of its applications. This is considered to be extremely important, because it is a necessary condition for avoiding a new 'computer literate' elite, which means, in turn, that all present and future teachers ought to be trained in the potential (for their work) of information technology: it will not, therefore, be desirable to restrict teacher training of those offering instruction in computer science.

For similar reasons, special attention should be given to pupils in special education, girls, and cultural minorities and/or those from specially deprived classes. As to the emancipation of women, it is stated that both sexes should have an equal chance to learn about information technology: such opportunities might presuppose that this activity should also be part of the curricula of schools traditionally attended by many girls (for example, numerous lower and middle vocational schools); that courses in information technology should not deter those included to avoid maths and science, and that good career education is virtually indispensable. Given this socio-cultural perspective, it is suggested that pilotprojects should be introduced at all educational levels and used as the basis for decisions about the implementation of a policy for each type of school after a four-ycar period"[2].

An important source of information for the policy report was a comparative study, analysing the policies of six Western countries (England, Wales and Northern Ireland, France, Federal Republic of Germany, Denmark, Scotland and the U.S.A.)[3]. This report was conducted by the European Cultural Foundation and it appeared in June 1982. The analyses of the educational policy of the mentioned countries resulted in ten key-issues [4].

The policy report elaborates some key issues, e.g. computer literacy should be a compulsory subject matter for all children. The development and dissemination should start with a first period of 2 years of school experiments within broad boundaries, the so called " 100 -school project". This should be followed by a period of more systematic and organized development.

A second development in the field of Information Technology in education was the first report of the Advisory Committee in December 1982. The Committee fully support the idea of "computer literacy for all". The Committee distinguishes between learning about, with or through Information Technology and advises the minister to put, during forthcoming years, emphasis on learning about Information Technology for all pupils, particularly in the first phase of secondary school[5].

This first phase contains the grades 7, 8 and 9 (ages 12,13 and 14). One can choose between 4 types of schools: the pre-university school, the higher and middle general secondary education and finally the lower vocational education. The first year (grade 7) is often organized as a transition year, for two or more types of schools. The first phase of secondary education is compulsory for all children. So, as the committee agrees, all children have equal access to a minimum of information technology. Learning about Information Technology can be described as computer literacy, involving not only programming, but also underlying issues of social impact. The Committee's meaning is also labeled with the term "computer science for citizens" to indicate that all citizens have to have some elementary notion of computers and information technology in order to be able to function in our contemporary society.

Another argument the Committee is giving for its choice is an innovative one. Taking into account the reluctance to change within education, this innovation concerning Information Technology had better be introduced in a simple form at the outsel, before gradually stepping up its complexity. So learning about Information Technology in lower secondary education means:

(i) less complex curriculum and software development;

(ii) less radical changes in school and classroom organization; 
(iii) less complex and expensive hardware, with the latter consideration of importance in realising equality of access[6].

A third, new component within Dutch Education is the 1-year-old Centre for Education and Information Technology (COI). This Centre forms, logether with the policy report and the advisory report, for a great part the Dutch "computer in the school" scene. It has been founded and financed hy the Ministry of Education and Sciences to transfer knowledge about the latest scientifical and technical developments about computers to the applications and correct use of it in education [7]. The primary tasks are:

(1) to inform Dutch schools and other Educational Institutes about the possibilities of applying (micro) computers in teaching and learning;

(2) to advise them how to apply the available information;

(3) to stimulate an accountable use of computers in education;

(4) to maintain contacts with national as well as international institutions and associations;

(5) to participate in (inter)national initiatives for co-operation;

exchange of information

standardization of information systems and educational software.

The COI has to be a scientific centre which on the one hand informs schools and other service-institutes within the education system in The Netherlands and stimulates activities in this field and on the other hand has an important function in the co-ordination of activites as chairman of a "National Committee on Education and Information Technology" an advising-function to the Department of Education.

There are several other institutes which have a task in the innovation processes and in introducing computers in schools [8]. There are: (a) three National Educational Centres, supporting the schools with the implementation of projects on a national level; (b) the teacher training colleges, also responsible for inservice training; (c) the National Foundation for Research on education (SVO), which co-ordinates the research executed by universities and educational research centres; (d) the National Institute for Curriculum Development (SLO), responsible for the computer literacy curriculum. Although The Netherlands is a small country, there are so many different institutions and groups involved in the innovation of Information Technology in education, that special attention has to be payed at the co-ordination between the various activities.

In the next section it will be explained how the ideas and the priority for learning about Information Technology are given concrete form.

\section{COMPUTER LITERACY}

The most important project on learning about Information Technology in the lower secondary education is the so-called " 100 school project". This project, set up by the Ministry of Education and Sciences, started in September 1983 and is financed by the Department of Education and Sciences and the Department of Economic Affairs. The latter is willing to support the schools in purchasing the equipment or software, provided that such have an innovative impact on Dutch industry. A 5-year 24 million guilder budget is available for this purpose.

The first phase of the 100 -schools project takes 2 years and will have the character of a preliminary exercise for the schools. With the mentioned support of the Department of Economic Affairs, each of the participating schools could obtain the loan of 8 microcomputers. More than 700 schools were interested in the participation in this project.

The complete innovation project has threc features:

(i) Comprehensive: Curriculum development, teacher (-inservice) training, research and general educational support will be integrated in one general innovation strategy. For this purpose a national co-ordination committee has been founded. In this committee different groups, which have a direct or indirect task in the innovation process, are participating.

(ii) Problem solving approach: The starting point of the second and following phases of the project will be a complete analysis of the situation and problems concerning computer literacy in 
the schools, i.e. an analysis of the actual and desired situation and the determining of the discrepancies. This will be a special task for the research institutes.

(iii) Responsive: The actions and interventions of the innovators have to respond to the perceived needs and desires of the teachers and the schools, who-like mentioned in a previous section-have an autonomy in arranging their own curricula and a certain amount of freedom to reject the innovators' offer.

\section{THE SURVEY}

Because of the freedom teachers and schools have in arranging their curriculum, there is a great diversity between the schools. And because of the set up of the 100-school project (i.e. a 2 year phase of preliminary excercises), there will also be a great diversity in the ways the participating schools will give concrete form to the concept of computer literacy.

In a planned problem solving approach, it is necessary to have information about the actual situation of the schools in general and the activities and ideas of the schools concerning computer literacy in particular. Leithwood has elaborated this idea in a strategy for implementing curriculum innovations [9].

Leithwood stated that the first diagnostic task in the strategy is to identify the goals to be accomplished by implementing the innovation [10]. In the case of the 100-school project, this will be done by the National Institute for Curriculum Development in co-operation with other educational institutes.

Leithwood continues: "The second task in the implementation strategy is to determine how present classroom practices compare with those practices suggested by the innovation" [11].

To provide for this information, the Department of Education of the Twente University of Technology will carry out in Spring 1984 a nationwide survey in lower secondary education schools to make an inventory of:

(i) The school organization and the competencies of the staff and teachers, the audio-visual and computer facilities and their use, and other facts concerning the school.

(ii) The ideas and experiences on computer literacy, e.g. the used software, the topics and the content of the computer literacy curriculum, ideas concerning the inservice training, etc.

(iii) The views teachers and staff have on the implementation of an innovation, e.g. the desired facilities concerning materials and people, experiences with other innovations, the necessary curriculum products, etc.

After identifying the desired situation, the actual situation and the relevant differences between them, the following phases in Leithwood's approach contain the identification of the obstacles preventing the differences from being reduced and the designing and carrying out of procedures to bridge over these discrepancies. So the next step, after the survey, will be the construction of a plan of action. This plan will be drawn up and carried out by the several educational institutions, in co-operation with the Ministry.

Because it is important that these have the disposal of all the relevant information, they will be consulted during the construction of the survey.

The co-ordination of the different innovative actions will be a task for the Co-ordination Committee on Education and Information Technology.

The Survey will be organized as a postal questionnaire. The population of about 2700 lower secondary schools will be divided into three sub-groups:

(i) the participants in the 100 -school project;

(ii) the 650 schools which were interested in the participation in the project, but which were not selected;

(iii) the remaining 2000 schools.

From the sub-populations (ii) and (iii) samples will be drawn. By comparing and analyzing the data of these three subgroups it is in all probability possible to gain more insight in the factors responsible for an interest in the use of computers in schools. 
As a starting point for the construction of the questionnaire, Fullan's list of 15 factors affecting implementation will be used[12]. Some of these factors - e.g. the principal-are typical North American factors and not so relevant to the Dutch situation. Nevertheless, it seems that Fullan's factors provide a good theoretical framework for the construction of the questionnaire.

Being responsible for the organization and execution of the survey, I have good hope that the planned inquiry contributes to an effective innovation of computer literacy in The Netherlands.

\section{REFERENCES}

1. Akkermans J. and Plomp T. J., Information technology in Dutch education: will there be a national policy? Eur. J. Educ. 17, 411-420 (1982)

2. Ibid. p. 417.

3. Ceryich. L., Computer education in six countries: policy problems and issues. English language report prepared for The Netherlands Ministry of Education and Science, by the European Institute of Education and Social Policy, Paris, June (1982).

4. These key issues are: 1-three meanings of computer education. What is computer literacy? 2-which educational levels should have priority?; 3-informatics for all vs informatics for a few: optional or compulsory computer education; 4-teacher training; 5-software; 6-hardware; 7-what should be the role of universities; 8 -the research and education service sector; 9-some psycho-sociological factors; 10-how expensive is a national computer education policy.

5. Advisory Committee on Education and Information Technology (Chairman: Tjeerd Plomp). Advisory Report, November (1982) (in Dutch).

6. Akkermans J. and Plomp T. J., op. cit.

7. Centre for Education and Information Technology (COI), Information brochure, Enschede (1983).

8. National Institute for Curriculum Development (SLO), Information brochure, Enschede (1982).

9. Leithwood K. A. (Ed.), Implementing curriculum innovations. In Studies in Curriculum Decision Making. OISE, Toronto (1982).

10. Ibid., p. 256.

11. Ibid., p. 260.

12. Fullan M., The Meaning of Educational Change. OISE, Toronto (1982). 